\title{
Common Metamodel of Questionnaire Model and Decision Tree Model
}

\author{
Mirza Suljic ${ }^{1, *}$, Edin Osmanbegovic ${ }^{1} \&$ Željko Dobrović $^{2}$ \\ ${ }^{1}$ Department of Digital Economy, Faculty of Economics, University of Tuzla, Bosnia and \\ Herzegovina \\ ${ }^{2}$ Department of Information Systems Development, Faculty of Organization and Informatics, \\ University of Zagreb, Zagreb, Croatia \\ *Corresponding author: Department of Digital Economy, Faculty of Economics, University \\ of Tuzla, Bosnia and Herzegovina. E-mail: mirza.suljic@untz.ba
}

Received: August 30, 2018 Accepted: September 18, 2018 Published: September 25, 2018

doi: 10.5296/rae.v10i3.13540ＵRL: https://doi.org/10.5296/rae.v10i3.13540

\begin{abstract}
The subject of this paper is metamodeling and its application in the field of scientific research. The main goal is to explore the possibilities of integration of two methods: questionnaires and decision trees. The questionnaire method was established as one of the methods for data collecting, while the decision tree method represents an alternative way of presenting and analyzing decision making situations. These two methods are not completely independent, but on the contrary, there is a strong natural bond between them. Therefore, the result reveals a common meta-model that over common concepts and with the use of metamodeling connects the methods: questionnaires and decision trees. The obtained results can be used to create a CASE tool or create repository that can be suitable for exchange between different systems. The proposed meta-model is not necessarily the final product. It could be further developed by adding more entities that will keep some other data.
\end{abstract}

Keywords: Metamodeling, Questionnaire model, Decision tree model 


\section{Introduction}

Modeling can be seen as a process closely connected to the way humans think and solve problems, i.e. the way how a person links a sequence of facts which he or she encounters and acts upon. The development of science and technology have led to formation of different ways of acquiring models, and all because of the need to allow the description of complex phenomena, so they could be precisely described, observed, analyzed and solved. A model as a result of the modeling process represents a general system image, i.e. abstract non-material system representation from the real world (Nordstrom, Sztipanovits, Karsai, \& Ledeczi, 1999; Rosemann \& Zur Muehlen, 1998). Therefore, we can say that the formulation of the new models as the result of observation of the real world nowadays represents one of the basic roles of modeling. From the aspect of IT system development, a model represents a subjective, general system image, describing the system elements and its connections (Matić, 2004), which allows better understanding of the structure and system functioning.

Everyday practice of IT systems development is different, but one of the factors that reduces the risk of wrong development of the real world system is the timely development of a real system model before the system itself is created (Milicev, 2009). As the real systems vary in their complexity, they can be presented with many different models. Well-designed model should include all the necessary elements about the system described and avoid irrelevant elements considering the level of abstraction. The effort invested in complex model development should emphasize the importance of using adequate modeling techniques (Bézivin, 2001). In order to facilitate the creation of the model, different modeling languages have been created (Nordstrom et al., 1999). Choosing the appropriate modeling language is not a simple task, considering it should fit the characteristics of the real problem that needs to be solved. (Brinkkemper, Saeki, \& Harmsen, 1999). Different methods are used to solve real problems that are constantly being posed to the organization. Integration method is often used in order to ensure methodologically accurate way of real problem solving. Integration method involves relationship definition between different methods, so they can be productively used together for problem solving. In this context, the method of metamodeling has also been found.

There are several studies in which the application of metamodeling involves the integration of two or more methods, for example integration of methods: data modeling, process modeling and final machines (Dobrović, 1998; Dobrović, Brumec, \& Tomičić-Pupek, 2005), integration of methods: strategic planning and SWOT analysis (Dobrović, 2001), integration of a method: Seven Habits of Highly Effective People and Process Support HelpDesk (Medic \& Dobrovic, 2013), integration of methods: strategic planning, SWOT analysis and Balanced ScoreCard (Tomičić Furjan, 2016). The mentioned studies have shown that by using meta-modeling a comparison and integration method can be done on a higher "meta" level of abstraction. Therefore, modeling the model at a higher level of abstraction, that is, "meta-modeling" has become a new challenge whose concepts and application methods involve connecting different methods in methodology, and applying their findings to various fields of science. In short, according to (Dobrovic \& Lovrencic, 2013) metamodeling is the modeling of reality with a particular purpose. 


\section{$\Lambda$ Macrothink}

This paper observes metamodeling through a prism of possible application in creation of a meta-model for various methods which are used in science, as well as a decision-making support. The models, along with the meta models in this paper, were created by structuring known concepts "from appearance to object" (Hay, 2010; Rosemann \& Zur Muehlen, 1998), where the reality (real-world things, data about real-world things, data about a database and elements of metadata, i.e. objects) is raised to the abstraction level of the described object through four levels of abstraction. This paper is based on the creation of a meta-model of two known methods - the survey method and the tree decision method. The paper is divided into four chapters. In the second chapter, the way of using these methods is presented with the conduct of scientific research and survey method, and decision tree method is explained theoretically. In the same chapter, the listed concepts are structured in the "appearances table", based on which the business and data ERA model is made. The third chapter presents a common meta-model. The last chapter is a conclusion that suggests the possibility of further research related to the created meta-model.

\section{Description of Methods}

Nowadays, in an environment which is global, operative in real time, highly competitive and constantly active, scientific research can be seen as a complex process which as a whole encompasses a large number of interconnected actions which can be implemented through several separate phases. Reviewing the phases of carrying out scientific research with application in economy can be presented through a series of steps (Kukić \& Markić, 2006). Since economy as empirical social science is predominantly based on quantitative research methods, one of the most commonly used methods for data collection is the survey method, while the decision tree method is used as an alternative way of displaying and analyzing the decision-making situation. These two methods are not completely separate, but on the contrary, there is a strong natural connection between them. Therefore, according to today's most commonly used system approach, these two methods can be seen as a whole (subsystems) of a single system. All data collected by the survey method can be globally seen as entering a dynamic system for processing and information transferring, and on its output there is a tree decision method as a decision-making subsystem. Therefore, all data flows that appear cumulatively contribute to the common model, which is created by modeling their information content. One of the preconditions for the development of a common meta model is the existence of a unique methodology (Dobrović, 1998) of meta model creation which includes data derived from all methods. The model of the "appearances table" (Hay, 2010) is used to construct a survey method model and the tree decision model. For simplicity reasons, not all incidence related to the model from the real world are listed, instead the concepts that are necessary for the creation of a common meta model survey method and the tree decision method are set out.

\subsection{Survey Method}

The survey method represents a process which is based on the questionnaire and it uses an organized and methodical way to collect data, information, views and opinions on 
representative samples of the population which is the subject of research, and it also uses well defined concepts, methods and procedures. Collecting data using survey as a separate technique, belongs to the empirical methods of data collection. The survey is conducted on a sample of the population, so that the researcher could use the information obtained to make conclusions concerning the wider population. It shows that two concepts need to be clarified regarding the survey method. One is the concept of a sample, and the other is the concept of a questionnaire. The sample, therefore, is nothing but a part of a total population that is a subject of the survey. An error in applying the survey method is most often caused by a sample error. So, the sample must be representative, i.e. it has to own all the features of the group it represents. While the questionnaire is nothing more than a technical tool, an instrument to conduct a survey and collect data on individual population samples, it consists of a number of questions related to the subject of the research to which the response is needed.

According to (Zelenika, 2000) before carrying out a scientific research using the survey method, it is necessary to determine the purpose and goals of the research. The purpose and goals must be set realistically so they can be accomplished by the survey, i.e. lead to the proving hypothesis. Before the researcher begins to compile questions, it is necessary to select the technique of data collection (Horvat, Marković, \& Kuleš, 2002). It requires a lot of attention, because it can affect the quality of the collected data and significantly jeopardize the other steps of scientific research. We usually think of two basic types: classic questionnaires and interviews. Both of these methods, according to (Dumičić \& Žmuk, 2009), can be carried out with or without the help of the interviewers and according to the type of a survey questionnaire, paper or electronic. Keeping in mind that the written survey, which is filled out by the respondent himself, should not last more than 30 minutes, and the oral poll conducted by the interviewer should not last for more than 40 minutes.

When preparing the questionnaire, it should be taken into consideration that the scope of the survey, i.e. the number of questions and sub-questions that will be covered by the survey, depends not only on the wishes, needs and possibilities of the researchers, but also on the willingness of future respondents to cooperate. The content of the questions should be theoretically grounded, i.e. questions should be based on the practical application of the following three areas: the research subject knowledge, knowledge of the psychology of attitudes and opinions, as well as the theoretical conception of the metric characteristics of each variable. Questions are not included in the questionnaire accidentally, because each of them refers to an indicator. The indicator refers to a variable, a variable on a hypothesis, and a hypothesis on a problem (Vujević, 2002). So, every question in the questionnaire should be formulated to be in the function of the research problem. Recommendations about the formulation of the questions are included in the works of Supek and Buble (Buble, 2010; Supek, 1968). Questions can be open type or closed type. Both kinds have good and bad sides. Open questions should be used in the preparatory phases of the research, because they have a higher heuristic value, so they can help with the hypothesis set up and with the construction of closed questions. Closed questions are used in verification studies. They allow generalizations, so by using them, it is possible to check certain hypotheses. Therefore, the 
final questionnaire in verification studies is typically composed of closed questions. Questions can also be direct and indirect, depending on how we want to get the opinions, facts, information or a phenomenon about something from the respondents.

\subsection{Survey Metamodel}

In order to better understand the very model of the survey, and to facilitate the understanding of the connection between the survey model and decision tree model, a meta-model of the survey model should be defined. To define meta-model, it is necessary to understand the concepts of the very model of the survey. The survey model, as a result of logical design of the information system, answers the question: How to collect data when conducting scientific research? In order to answer this question as easy as possible for understanding, a graphic presentation of the model is used in the form of questionnaire, for example. A questionnaire, as a part of the survey method is designed to consist of a number of questions related to the subject of the research to which the response is needed. Therefore, when conducting a research, data collection is carried out using one or more questionnaires, while one questionnaire always belongs to only one study. The questionnaire can have more questions, while the same question can (again) be used in different questionnaires. Also, when creating a questionnaire, it is needed to define a set of questions according to the predetermined order which are presented to the respondents. The questionnaire usually has two parts: the first part consists of general questions (about the respondent, about the organization, etc.), and the second part of the question relates to the topic of the research. Every question is linked to a type of question (Yes / No, Text, Scale estimates, Likert scale, etc.).

Collecting data using questionnaires is generally conducted by interviewers, whose number can be higher, while the same interviewer can participate in the implementation of several different questionnaires. Also, one of the concepts of Survey method is also the respondent. The respondent is a part of the selected part of population upon which the social phenomenon study is performed. One respondent can only fill in the questionnaire once, giving answers to questions that are an integral part of the questionnaire. Also, one respondent can participate in completing several different questionnaires, as long as he forms a part of the population for whom a research is conducted. The answer as the concept of the survey method has the role of storing the collected data. Data storage can be a sort of challenge because it is necessary to connect the questionnaire, the record, the question and the answer of each respondent who completed (filled in) the questionnaire. It is important to mention that the Answer entity does not relate to the answers which are connected to a certain question on the questionnaire, but it refers to a set of data collected by filling in a questionnaire.

Besides the already mentioned roles in conducting the survey method research, the bearers of the activities can have the following roles: the client and the researcher. The client usually represents an organization which has a practical problem, and practical suggestions for solving the problem are expected from the research. Therefore, one client can make an order for multiple research, while one research usually has just one client, which is one of the limitations of the future model. The researcher usually focuses on discovering the problem of the research within the practical problem in order to realize how to act to solve the problem. 
Therefore, a research can be conducted by one or more researchers, while one researcher can participate in more studies. Since the interviewer, respondent, and researcher represent entities with common attributes, they are grouped and presented with the concept of a Person. Since one person cannot be a researcher, an interviewer and a respondent at the same time, then each person can participate in only one of the listed statuses.

We ignored other concepts from the theoretical part, so that the model would not be too complex. The concepts of data collection techniques, sampling methods, and the concept of the relationship between questions, hypotheses and research subjects are omitted. In Figure 1, the presented meta-model is composed of seven basic entities with which the survey method can be shown.

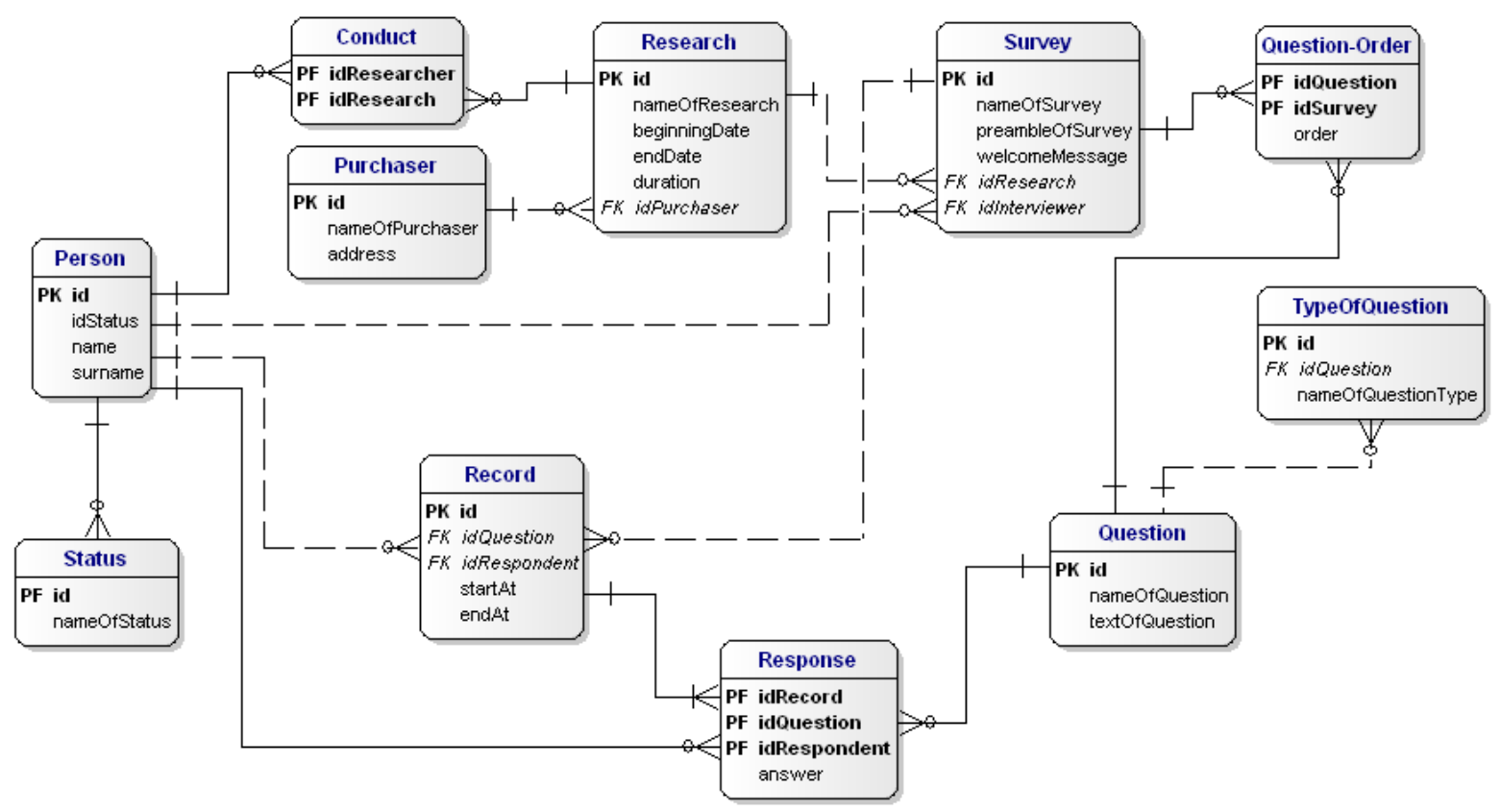

Figure 1. ERA Meta-Model of Survey Method

Many-to-many relationships from the presented business model are separated in the data of ERA model into two connections which connect the basic or strong entities by using weak, i.e. embedded entities (Chen, 1976; Strahonja, Varga, \& Pavlić, 1992). As a result of breaking the links, we have the "Conduct", "Question-Order" and "Answer" entities which are not present in the business model, that have the task of extra storage of additional data.

Therefore, we can say that the meta-model of the survey is a data model about the concepts of the questionnaire model. In other words, the meta-model contains data about the questionnaire, question, question-order, type of question, answer, record, interviewer, respondent, researcher, client and the research. Surveys can be used to create a questionnaire model and to document the knowledge gathered by this method. Besides that, this model represents the core for making CASE acts which supports the Survey method. The Survey Method meta-model is shown in the Figure 2. 


\subsection{Decision tree Method}

Decision trees as a method appear in two scientific areas: decision analysis and machine learning. The decision analysis is used to visually (graphically) present the decision-making method by an expert (Banjanović-Mehmedović, 2011). Those kinds of decision trees describe the way a human expert comes to a decision when solving a decision problem, e.g. buying a car, selecting a company's location, diagnosis in medicine, etc. In machine learning, the decision tree allows the modeling of prediction and classification problems (Kantardzic, 2011; Song \& Ying, 2015). The modeling results are models that can be interpreted in a comprehensible form, i.e. it is possible to draw out the rules from the models which are completely understandable in terms of the issues that the model describes. Those models are used in data mining, i.e. searching for hidden connections between the data. Those kinds of trees are based on data, and they are also called: classification trees and / or regression trees. Classification and regression trees are a method that provides a graphical representation of the model and the impact of the input variables on the output, when the output variable must be expressed in the form of a class or a category.

Decision trees (Giarratano \& Riley, 1989; Quinlan, 1986), in addition to enabling the display of knowledge, also serve in the conclusion by using knowledge. They are based on the method called "divide and rule" where the set of examples is subdivided into subgroups and the process of division is recursively repeated until there is one example that actually classifies knowledge. The decision tree represents the way of classifying the attributes in relation to the given target variable. A positive characteristic of the decision tree is the ability to easily interpret the results of processing in the form of the corresponding rules. Visual interpretation of the decision tree is a flow diagram represented by a tree structure (Figure 2). In each internal node, a condition over an attribute is examined, and each branch of the tree represents one outcome of the test. Branches connect "parental nodes" to "children's nodes". A parentless node is called a "root node", and nodes without children are "leaves". The leaves are marked by the names of the classes in which the examples are sorted. The leaves are also called "response nodes" because they represent all possible solutions to a given problem. All other nodes are "decision node ".

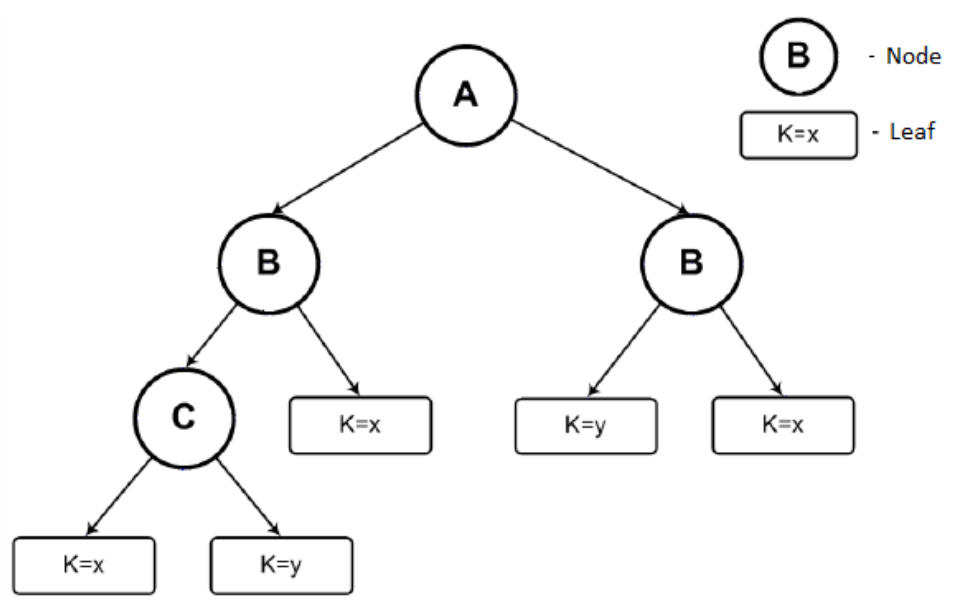

Figure 2. A Simple Decision Tree 


\section{Mll Macrothink}

Research in Applied Economics

ISSN 1948-5433

2018, Vol. 10, No. 3

Classification of examples by a decision tree is conducted by following a specific path from the root of a tree to some of the leaves. Mechanisms for forming a decision tree are algorithms which automatically build a decision tree based on a given data set. The principle of the algorithm is to follow the movement of the first node towards the last one and to classify it on the basis of the value of its attributes to a particular class. In most cases, the goal is to find such a decision tree, that the classification error is the number of nodes that the tree must have or the average depth of the tree should reach the minimum.

The basic algorithm of the decision tree is the ID3 algorithm developed by J. Ross Quinlan (Quinlan, 1986) based on the Concept Learning System (CLS) algorithm (Gamberger \& Šmuc, 2001). ID3 is one of the classification algorithms which is used to solve the problem of the importance of attributes in the overall decision-making or classification. Later versions of the algorithm (CART (Breiman, 2017)) and C4.5 (Quinlan, 1986)) improved the classification performance by enhancing some of the limitations of the original algorithm. In the tree creation phase, the algorithm starts with the entire set of data in the root node. The data set is partitioned according to the separation criteria in sub-groups. This procedure is repeated recursively for each subset until each subgroup contains only members belonging to the same class or until it is small enough. In the second phase - the decision tree is shortened to prevent excessive adaptation to the learning data and to improve the accuracy of the decision tree.

\subsection{Decision Tree Metamodel}

Creating a decision tree model is a scientific research activity, which follows after the data collection. Using the survey method, data were collected, and the basis for modeling the decision-making phase was obtained. The method for modeling the decision-making phase is a defined procedure of finding and displaying models, from which it is possible to derive rules that are completely understandable in terms of the problems which the model describes. Decision tree metamodel, as a result of the logical design of the decision-making method itself, needs to better understand and demonstrate the concepts related to the decision tree method. The graphical presentation of the model is made to visually introduce the way of decision making by an expert or the presentation of the prediction model in the modeling of classification problems. The decision tree model includes concepts such as: node, branch, and leaf. The decision node is the point at which the choice has to be made, in Figure 2 it is shown as a square. Every decision node has a name and a position. Lines that spread from the decision node are branches; every branch is one of the possible alternatives or actions that are available at that moment. The set of alternatives must be mutually exclusive (if one is selected, the other one cannot be selected) and comprehensive (all possible alternatives must be included). In addition, each branch connects two nodes ("parent node" with "child node"), regardless of whether the "child node" is the node of a decision or a leaf. The leaf represents the destination of one branch and it is defined by the position and class (category) i.e. the mark of the object to which it is classified. Class represents a categorical variable. Therefore, the structure of the decision tree is similar to a flow diagram in which each inner node represents a "test" for an attribute, while each branch represents the test result, and each node with a leaf represents a class mark, i.e. the destination of one branch. The path from the root 
to the leaf represents the classification rules and is equal to the number of leaves of some model decision tree.

Research is a broad term which is typically characterized by the features like: title, subject, beginning, and period of research. Each research is usually conducted by one or more researchers, with only one client, which is also one of the limitations in the model design process. On the other hand, the result of each research can be multiple models of the decision tree that always has one variable of decision, i.e. the aimed variable (attribute). Since decision trees are applied in solving classification problems, the variable of the decision or the aimed variable is always represented by the nominal value, i.e. it is represented by a set of values that can be taken by the decision variable.

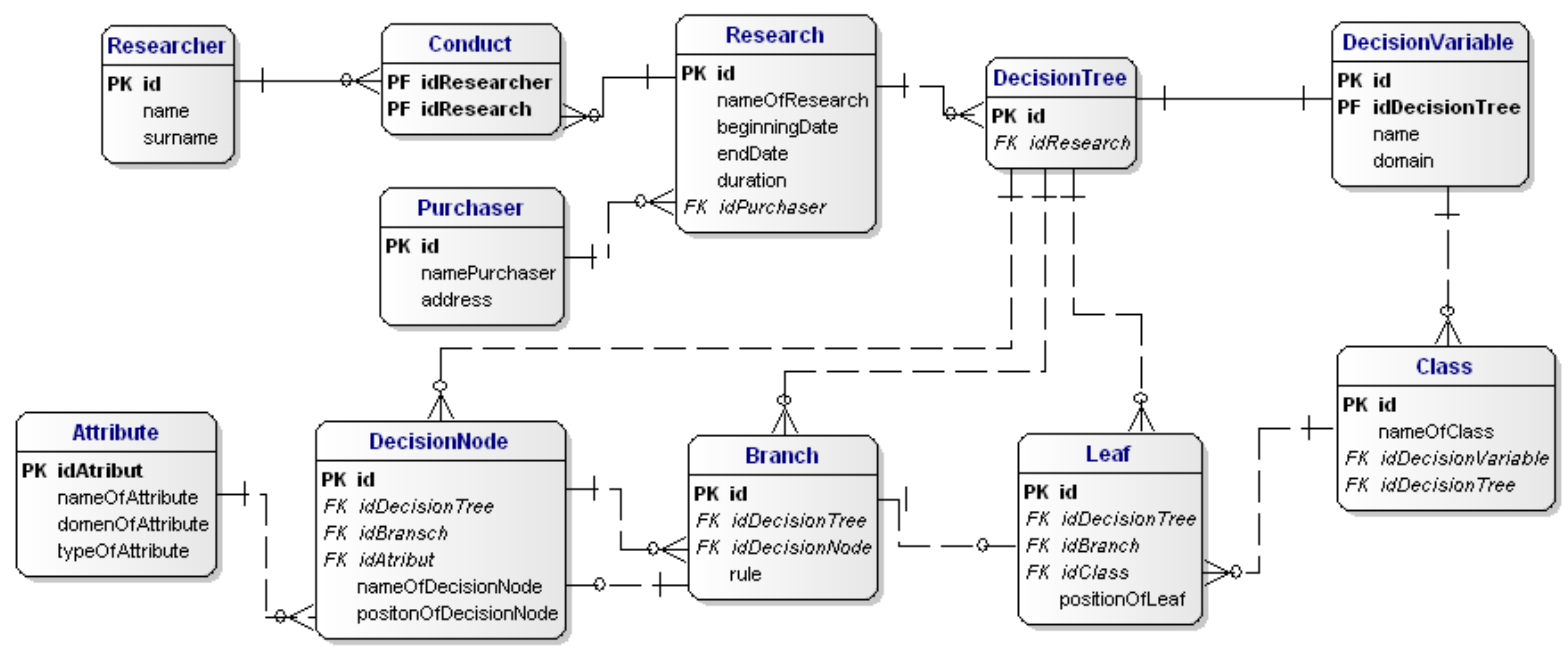

Figure 3. ERA Meta-Model of Decision Tree Method

As in the previous model of the survey method, many-to-many relationships from the business model shown are broken into two connections in the data (i.e.) ERA model, which the basic or strong entities then merge with weak, i.e. embedded entities. As a result of the breaking of connections, we have a "Conduct" entity that does not exist in a business model, and which has the task of storing data about researchers who conducted the research.

When creating the Decision tree metamodel from the incidence table, less important concepts related to a model from the real world are ignored, so the only shown concepts are those which are important for the final business (logical) and data (ERA) model of the described method. So, the table shows the following concepts: ORGANIZER, RESEARCHER, RESEARCH, DECISIONTREE, DECISIONNODE, BRANCH, LEAF, DECISIONVARIABLE, ClASS and ATRIBUT. The other mentioned concepts in the method description were ignored or simplified, so that the business model would not be too complex. For this reason, a business and data model are presented, showing ten basic entities by which the decision-making method is shown.

The obtained meta model of the decision tree method is a data model about the concepts of a decision tree. In other words, the decision tree method allows the creation of a decision model, and its meta-model allows the storage and documentation of the knowledge gathered by applying this method. 


\section{Common Metamodel}

As mentioned above, we attempted to integrate the two methods: questioning and decision trees, with the aim of modeling the system which integrates two phases of the scientific work. Phases of scientific work usually follow a generally accepted structure and they mainly consist of the same parts. The analysis of the carried out scientific research in the field of data mining concluded that the method of the survey and the decision tree can easily be integrated using a unique methodology (Dobrović, 1998) for development of a common meta-model; which initiated the proposal of a general integration framework of survey method and the decision tree method. The connection between the survey method and the decision tree method is also visible in the works dealing with the development of the prediction model by using the decision tree algorithms on the data gathered in the survey method, where the interconnection can be seen clearly (Osmanbegović, Suljić, \& Agić, 2015). Besides that, application of the Zachman Framework (Zachman, 1999) and methodology of the common meta-model development (Dobrović, 1998) allows the overcoming of the complexity of constructing the common meta-model of survey method and the decision tree method.

The easiest way to show that the survey model and a decision tree model are naturally connected is through the common integrated meta-model of these two modeling methods. In other words, there must be a connection between the results gained through the application of the survey method and the decision tree. The meta-models of Figure 1 and Figure 3 will serve for this. The way of connecting is presented in Figure 4. The figure shows three sets of concepts (entities).

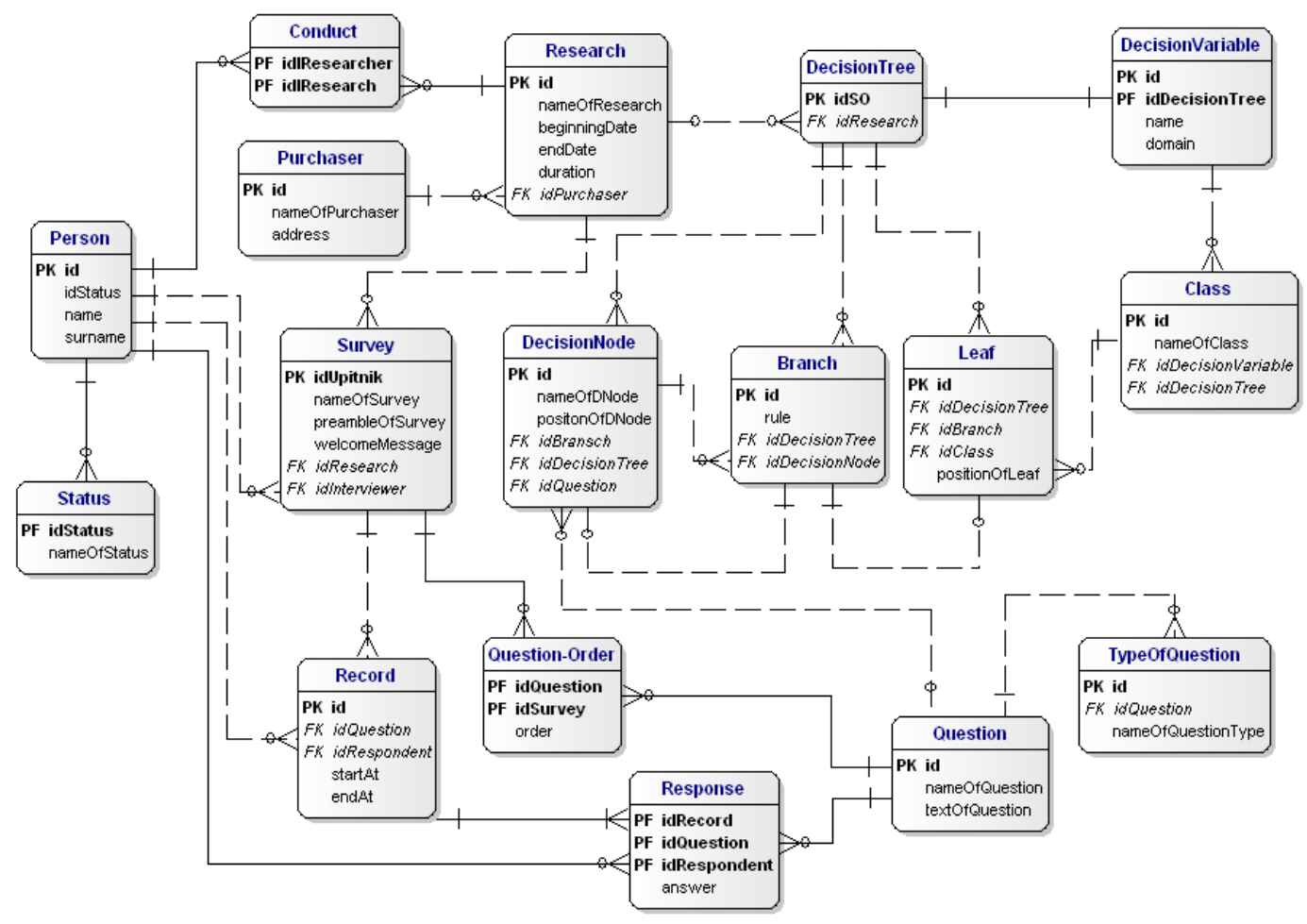

Figure 4. A common ERA model of the Survey Method and Decision Tree 


\section{Mll Macrothink}

Since the shown survey and decision tree methods present interconnected phases conducted in organizations dealing with scientific research, we can observe that the entities of the Researcher (Person), Conduct, Research, and Client are the first common entities that can be embedded in a common meta-model. Although at first glance it seems that the survey method and the decision-making tree do not have more common entities, that is not true. Entities Question and Attribute (decision node) actually refer to the same appearance, which is the target group of data on which the decision tree method should be implemented. Therefore, it is enough to use only one entity in a common model.

The second set includes the entities of the DecisionTree, VariableDecision, Class, DecisionNode, Branch, Leaf, which are elements of the meta-model of the decision tree method and represent different graphic elements of the decision tree. On the other hand, the third set has the results of modeling the survey method. So, for example, by modeling the survey method, the following entities were obtained: Questionnaire, Question, Question-Order, QuestionType, Answer, Record, Person and Status.

A common metamodel of the survey model and decision tree is presented in Figure 6. This way, we connected the meta-models of Figures 2 and 5, and gained the integration of methods into the methodology through the common meta-model which can be seen in Figure 6. This also helps ensure the aim fulfillment of well-defined methodologies, i.e. the survey method application results and the decision tree which makes the methodology as one meta-model. Figure 7 presents a proposal for the possible methodology application shown by the BPMN notation.

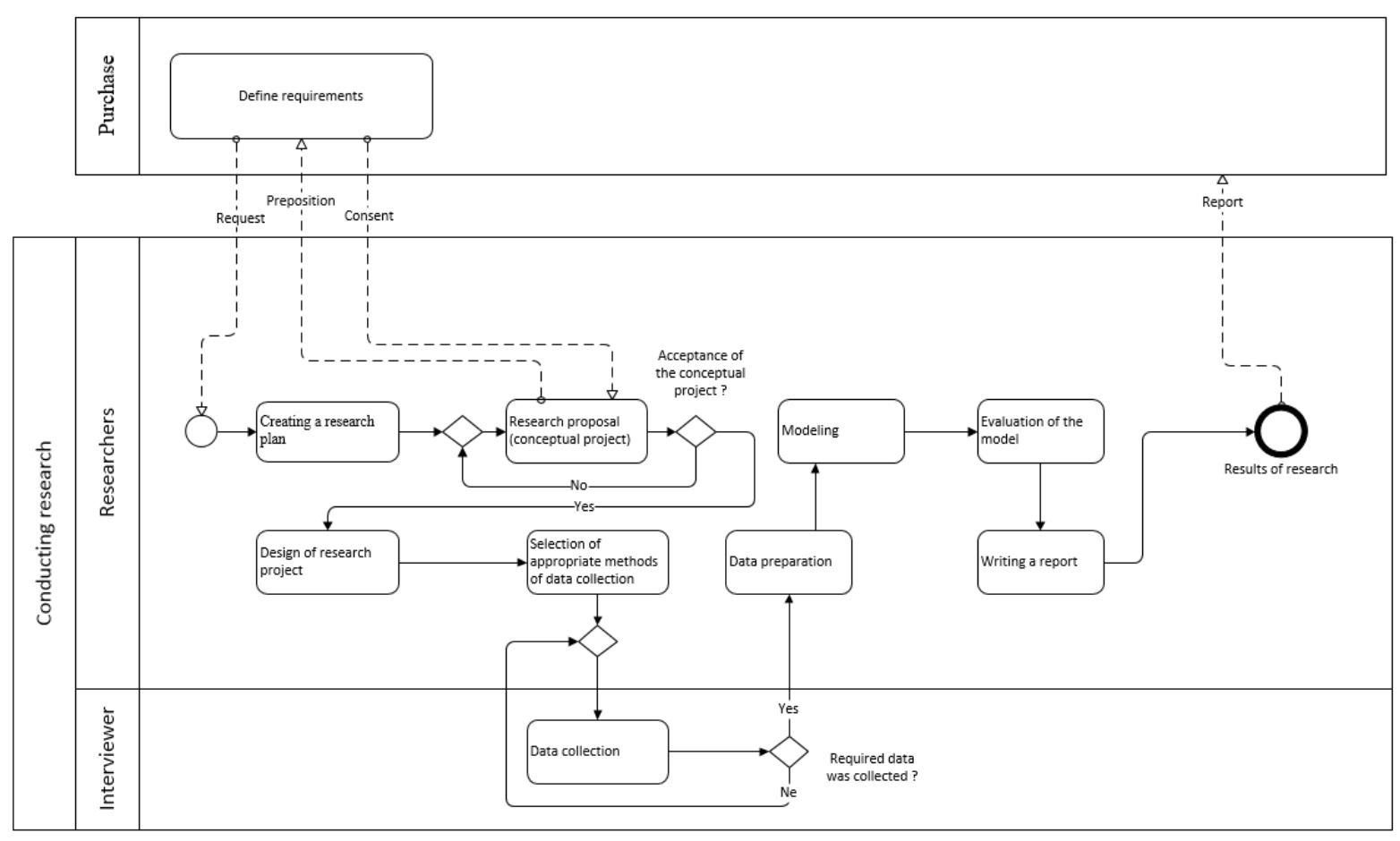

Figure 7. Steps in Applying the Proposed Methodology 


\section{Conclusion}

By applying modeling and metamodeling principles in this paper, we have presented how two different methods commonly used in science and in practice can be represented by one, common meta-model. The survey model and decision tree model are naturally connected, and their relationship becomes evident at the moment when we use the metamodeling method for a creation of a common model. The first step in modeling these is the understanding of the observed method concept. For this reason, the concepts of each of the two methods were presented in this paper.

The survey method allows the measurement and gathering of input and output variables related to a certain scientific research. Therefore, prior to carrying out the data collection using the survey method, it is needed to determine the purpose and objectives of the research in order for each collected data to refer to a variable, a variable to a hypothesis, and a hypothesis to the problem of research. So, the survey model answers the question "Which input and output variables need to be collected?". The answer to this question can be found in the appropriate survey model which comes as a result of the draft (plan) of the survey and the data collection plan. In any case, the important concepts of the survey model are questionnaire, question and answer.

The decision tree method presents an alternative way of showing and analyzing the decision-making situation. When using the decision tree method, the results of modeling are models which can be interpreted in a comprehensible form, i.e. in the form of a rule which can be derived from the obtained models. Essential concepts that describe the decision tree model are: decision tree, decision variable, decision node, branch and leaf.

Understanding the concepts which are related to each of the methods has highly facilitated their application in practice, i.e. through their mentioned examples. A table of incidence was created for each method, which was then used to create individual meta-models that contain the most important concepts on the survey method and the decision-making tree. Looking at a common metamodel which contains all the relevant concepts from both methodologies, we can easily use it in the implementation of the appropriate database. The obtained meta-model has a dual purpose:

- it provides an understanding of the survey and decision tree method modeling and

- it represents the basis for the development of a complete CASE tool which supports the survey and decision-making method.

However, it can be concluded that this methodology can be used to create tools which can ensure the development of a hybrid modeling method using decision trees. In the future, our hope is to expand the research into the creation of meta-models and some other methods used in machine learning, for example, neural networks or genetic algorithms. 


\section{References}

Banjanović-Mehmedović, L. (2011). Inteligentni sistemi. Tuzla: Harfograf Tuzla.

Bézivin, J. (2001). From object composition to model transformation with the MDA. Paper presented at the tools.

Breiman, L. (2017). Classification and regression trees. Routledge. http://dx.doi.org/10.1201/9781315139470

Brinkkemper, S., Saeki, M., \& Harmsen, F. (1999). Meta-modelling based assembly techniques for situational method engineering. Information Systems, 24(3), 209-228. https://doi.org/10.1016/S0306-4379(99)00016-2

Buble, M. (2010). Utjecaj organizacijskih varijabli na uspjeh programa unapređenja poslovnih procesa. Split: Ekonomski fakultet.

Chen, P. P.-S. (1976). The entity-relationship model—toward a unified view of data. ACM Transactions on Database Systems (TODS), 1(1), 9-36. https://doi.org/10.1145/320434.320440

Dobrović, Ž. (1998). Information System's Design and Development Methods for Object Systems with Time Changeable Functions. Fakultet organizacije i informatike, Sveučilište u Zagrebu.

Dobrović, Ž. (2001). Strategic Planning under Uncertainty: Building the metamodel. Journal of information and organizational sciences, 25(1), 11-26.

Dobrovic, Z., \& Lovrencic, A. (2013). Application of Formal Methods in Development of Information Systems. Paper presented at the Central European Conference on Information and Intelligent Systems.

Dobrović, Ž., Brumec, J., \& Tomičić-Pupek, K. (2005). Designing the Document Management System: Metamodeling Approach. Paper presented at the 16th International Conference on Information and Intelligent Systems IIS 2005.

Dumičić, K., \& Žmuk, B. (2009). Karakteristike korisnika interneta u Hrvatskoj i reprezentativnost internetskih anketa. Zbornik Ekonomskog fakulteta u Zagrebu, 7(2), 115-140.

Gamberger, D., \& Šmuc, T. (2001). Poslužitelj za analizu podataka [http://dms. irb. hr]. Zagreb, Hrvatska: Institut Rudjer Bošković. Laboratorij za informacijske sustave.

Giarratano, J. C., \& Riley, G. (1989). Expert systems: principles and programming. Brooks/Cole Publishing Co.

Hay, D. C. (2010). Data model patterns: A metadata map. Elsevier.

Horvat, J., Marković, S., \& Kuleš, M. (2002). Tehnike prikupljanja podataka. Ekonomski vjesnik: Review of Contemporary Entrepreneurship, Business, and Economic Issues, 13(1-2), 97-106. 
Kantardzic, M. (2011). Data mining: concepts, models, methods, and algorithms. John Wiley \& Sons. https://doi.org/10.1002/9781118029145

Kukić, S., \& Markić, B. (2006). Metodologija društvenih znanosti. Ekonomski fakultet sveučilišta u Mostaru, Mostar.

Matić, R. (2004). Razvoj informacionih sistema. Beograd: Beogradska poslovna škola.

Medic, A., \& Dobrovic, Z. (2013). Enhanced (meta) model for Helpdesk Support Services. Paper presented at the Central European Conference on Information and Intelligent Systems.

Milicev, D. (2009). Model-driven development with executable UML. John Wiley \& Sons.

Nordstrom, G., Sztipanovits, J., Karsai, G., \& Ledeczi, A. (1999). Metamodeling-rapid design and evolution of domain-specific modeling environments. Paper presented at the Engineering of Computer-Based Systems, 1999. Proceedings. ECBS'99. IEEE Conference and Workshop on.

Osmanbegović, E., Suljić, M., \& Agić, H. (2015). Determining dominant factor for students performance prediction by using data mining classification algorithms. Tranzicija, 16(34), 147-158.

Quinlan, J. R. (1986). Induction of decision trees. Machine learning, 1(1), 81-106. https://doi.org/10.1007/BF00116251

Rosemann, M., \& Zur Muehlen, M. (1998). Evaluation of workflow management systems-a meta model approach.

Song, Y.-Y., \& Ying, L. (2015). Decision tree methods: applications for classification and $\begin{array}{lllll}\text { prediction. Shanghai archives of psychiatry, } & 27(2),\end{array}$ https://dx.doi.org/10.11919\%2Fj.issn.1002-0829.215044

Strahonja, V., Varga, M., \& Pavlić, M. (1992). Projektiranje informacijskih sustava:(metodološki priručnik): Zavod za informatičku djelatnost Hrvatske

Supek, R. (1968). Ispitivanje javnog mnijenja. Naprijed.

Tomičić Furjan, M. (2016). Development of organisational performance measurement methodology using metamodeling. Sveučilište u Zagrebu, Varaždin.

Vujević, M. (2002). Uvođenje u znanstveni rad: u području društvenih znanosti. Školska knjiga.

Zachman, J. A. (1999). A framework for information systems architecture. IBM systems journal, 38(2/3), 454-470. https://doi.org/10.1147/sj.382.0454

Zelenika, R. (2000). Metodologija i tehnologija izrade znanstvenog i stručnog djela. Rijeka: Ekonomski fakultet. Mujanovid, Datzer, Budimlid-Imovinski kriminalitet u Bosni i Hercegovini prema zvaničnim statistikama. 


\section{Macrothink}

\section{Copyright Disclaimer}

Copyright for this article is retained by the author(s), with first publication rights granted to the journal.

This is an open-access article distributed under the terms and conditions of the Creative Commons Attribution license (http://creativecommons.org/licenses/by/3.0/). 